\title{
Regulation of Eicosanoid Pathways by MicroRNAs
}

\author{
Meike J. Saul ${ }^{1 *}$, Anne C. Emmerich ${ }^{1,2}$, Dieter Steinhilber $^{2}$ and Beatrix Suess ${ }^{1}$ \\ ${ }^{1}$ Department of Biology, Technische Universität Darmstadt, Darmstadt, Germany, ${ }^{2}$ Institute of Pharmaceutical Chemistry, \\ Goethe Universität Frankfurt, Frankfurt, Germany
}

Over the last years, many microRNAs (miRNAs) have been identified that regulate the formation of bioactive lipid mediators such as prostanoids and leukotrienes. Many of these miRNAs are involved in complex regulatory circuits necessary for the finetuning of biological functions including inflammatory processes or cell growth. A better understanding of these networks will contribute to the development of novel therapeutic strategies for the treatment of inflammatory diseases and cancer. In this review, we provide an overview of the current knowledge of miRNA regulation in eicosanoid pathways with special focus on novel miRNA functions and regulatory circuits of leukotriene and prostaglandin biosynthesis.

OPEN ACCESS

Edited by:

Dan A. Dixon,

University of Kansas,

United States

Reviewed by:

Carol Lutz,

Rutgers Biomedical and Health Sciences, United States Ranjan Preet, University of Kansas, United States

*Correspondence: Meike J. Saul saul@bio.tu-darmstadt.de

Specialty section: This article was submitted to Inflammation Pharmacology, a section of the journal Frontiers in Pharmacology

Received: 15 April 2019 Accepted: 26 June 2019 Published: 19 July 2019

Citation:

Saul MJ, Emmerich AC, Steinhilber D and Suess $B$ (2019) Regulation of Eicosanoid Pathways by MicroRNAs. Front. Pharmacol. 10:824. doi: 10.3389/fphar.2019.00824
Keywords: microRNA, new miRNA functions, eicosanoids, inflammation, prostaglandins

\section{INTRODUCTION}

MicroRNAs (miRNAs) are a family of small non-coding RNAs that regulate a wide range of biological processes including cancer development (Garzon et al., 2006; Croce, 2009; Ochs et al., 2014). In 1993, lin-4 was the first miRNA to be discovered in the nematode Caenorhabditis elegans (C. elegans) and it was found to regulate the gene lin-14 on the post-transcriptional level during C. elegans development (Wightman et al., 1993). Later, a second small miRNA involved in worm development, let-7, was identified (Reinhart et al., 2000). However, at the time of discovery, it was assumed that these RNAs were rare exceptions and only present in nematodes. In 2001, three independent publications reported the existence of several hundreds of these small non-coding RNAs not only in nematodes but also in murine and human cells (Lagos-Quintana et al., 2001; Lau et al., 2001; Lee and Ambros, 2001). Currently, more than 2,500 human miRNAs have been identified (http://www.mirbase.org), although the functions of many of them are still unknown. In this review, we will give a short overview of novel miRNA functions involved in inflammatory processes. Moreover, we summarize the recent findings on miRNAs regulating key enzymes of the eicosanoid signaling pathway.

\section{BIOGENESIS AND FUNCTIONS OF MIRNAs}

MiRNAs are transcribed from genes as long primary transcripts (pri-miRNAs) mostly by RNA polymerase II. In the nucleus, these pri-miRNAs are subsequently cleaved by the endonuclease Drosha. Drosha generates about 70 nucleotide (nt) long precursors (pre-miRNAs) that form imperfect stem-loop structures. Pre-miRNAs are transported out of the nucleus by exportin-5. In the cytoplasm, they are subsequently processed by a multiprotein complex including the RNAse III Dicer, Argonaute 2 (AGO2), and trans-activation-responsive RNA-binding protein (TRBP) to cleave the RNA into short 21-24 nt miRNA duplexes. Only one strand of the duplex is incorporated 
into a ribonucleoprotein complex, known as RNA-induced silencing complex (RISC). The passenger strand is mostly rapidly degraded. The miRNAs are then directed to their binding sites, which are usually located in the $3^{\prime}$ untranslated region (UTR) of their target messenger RNA (mRNA). Subsequently, they mediate endonucleotic cleavage, translational repression, or deadenylation of the mRNA transcript, followed by decapping and degradation of the target mRNA (Filipowicz et al., 2008) (Figures 1A, B). Of note, $40 \%$ of the currently known miRNAs are located within introns (mirtrons) and are processed by the spliceosome in an alternative way (Kim and Kim, 2007; De Rie et al., 2017).

Traditionally, it has been assumed that miRNAs are loaded into RISC and bind to their target mRNA through specific base pairing and that they reduce gene expression at the posttranscriptional level as their sole canonical function. However, there is recent evidence that miRNAs are also able to activate gene expression via a non-canonical mechanism (Figures 1C, D). miRNAs can bind to RNA-binding proteins (RBPs) and sequester them from their target mRNAs in a RISC-independent manner. This was shown for miR-328, which acts as an RNA decoy for the heterogeneous nuclear ribonucleoprotein E2 (hnRNP E2), a global post-transcriptional regulator (Eiring et al., 2010; Saul et al., 2016) (Figure 1C). As a consequence, hnRNP E2 target gene expression is activated.

Recent findings demonstrate that cells can secrete bioactive molecules (like proteins, lipids, or nucleic acids) from cell to cell via extracellular vesicles. Those vesicles can be divided into small extracellular vesicles (sEVs, also known as exosomes), microvesicles or apoptotic vesicles distinguished by their size (Thery et al., 2018). Although these extracellular particles were traditionally considered to be a "disposal system" for unnecessary membrane proteins (Johnstone et al., 1991), they have now captured the interest of researchers as part of the cell to cell communication (Wen et al., 2017).

In fact, sEVs $(<200 \mathrm{~nm})$ are highly concentrated with miRNAs (Goldie et al., 2014). Different cell types, including immune and cancer cells, are capable of secretion and uptake of extracellular miRNAs from sEVs. This suggests that sEVs could be part of the intercellular communication and carry out novel biological functions. Since the extracellular miRNA content does not necessarily reflect the cellular miRNA profile of the recipient cell (Zhang et al., 2015), the functional analysis of sEV-delivered miRNAs is an interesting subject. In a study focusing on noncanonical miRNA functions, which are receptor-mediated, it was demonstrated that two sEV-delivered miRNAs, miR-21 and miR29a, are able to bind to the murine toll-like receptor (TLR) 7 and the human TLR8 and induce cytokine expression (Fabbri et al., 2012). Similar results were found for miRNA let-7b in the context of the nervous system. Extracellular let-7b activates murine TLR7 and induces neurodegeneration. This observation is of particular interest because let-7b has been detected in the cerebrospinal fluid of patients with Alzheimer's disease (Lehmann et al., 2012). Thus, sorting of miRNAS into EV and the interaction of EV-delivered miRNAs with target cell components such as certain receptors seems to be an important way of cell-cell communication.

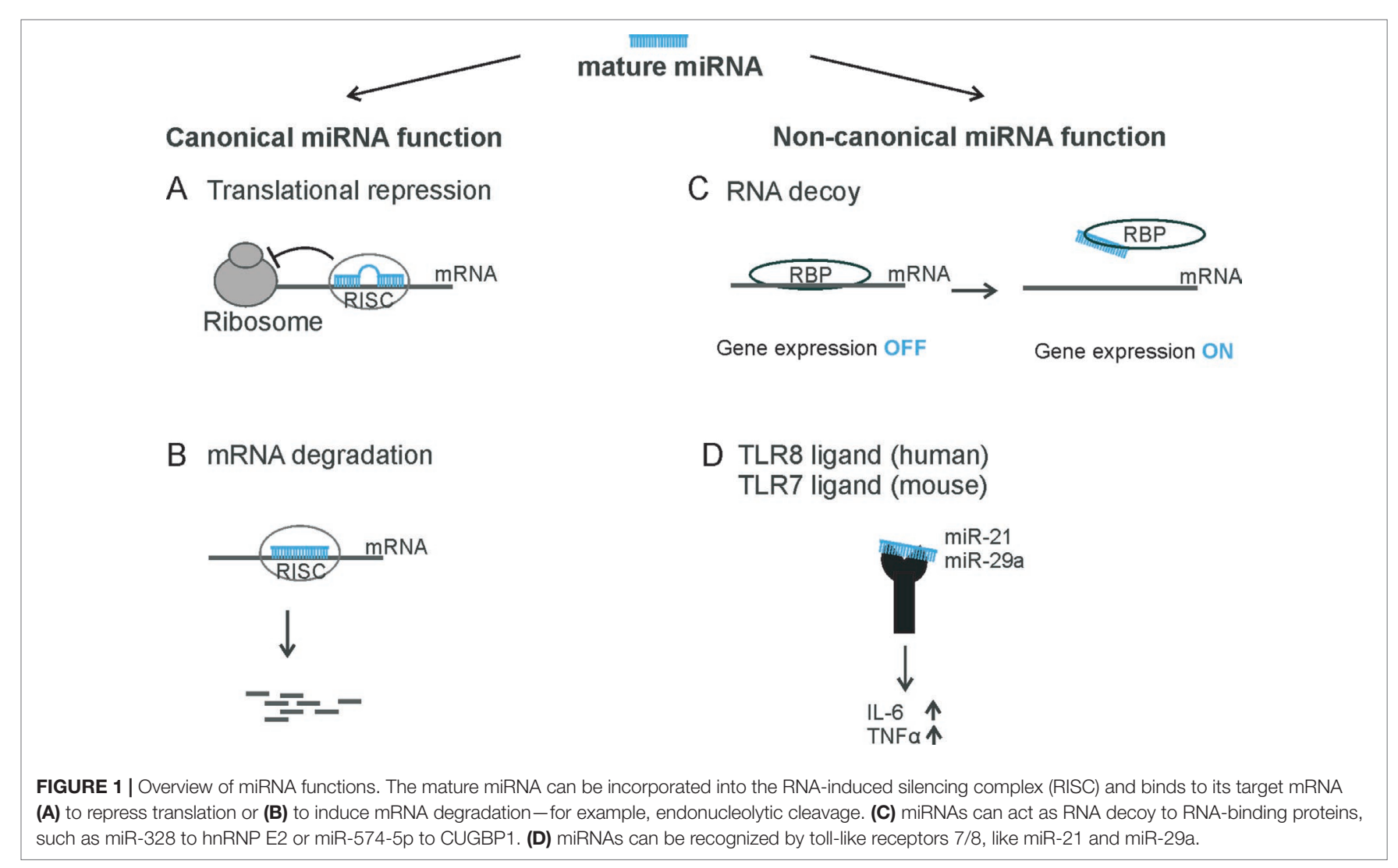


An interesting aspect for further investigations in this context is to explore how miRNAs are sorted into EVs. Initial studies demonstrated that miRNAs are specifically recognized by RBPs, such as hnRNP A2/B1 and Y-box protein 1 (YBX1). Those RBPs bind sequence-specifically to miRNAs and load them selectively into sEVs (Villarroya-Beltri et al., 2013; Shurtleff et al., 2016). These data suggest that the loading of miRNAs into EV is a specific process that might control biological processes such as immune functions.

\section{MIRNAS AND EICOSANOIDS}

Eicosanoids such as prostaglandins and leukotrienes are biologically active lipid mediators that are products of a local cell type-specific arachidonic acid (AA) metabolism (Figure 2). Such lipid mediators play a critical role in different pathological processes like inflammation and cancer (Zeldin, 2001; Wang and Dubois, 2010; Radmark et al., 2015). The synthesis of eicosanoids
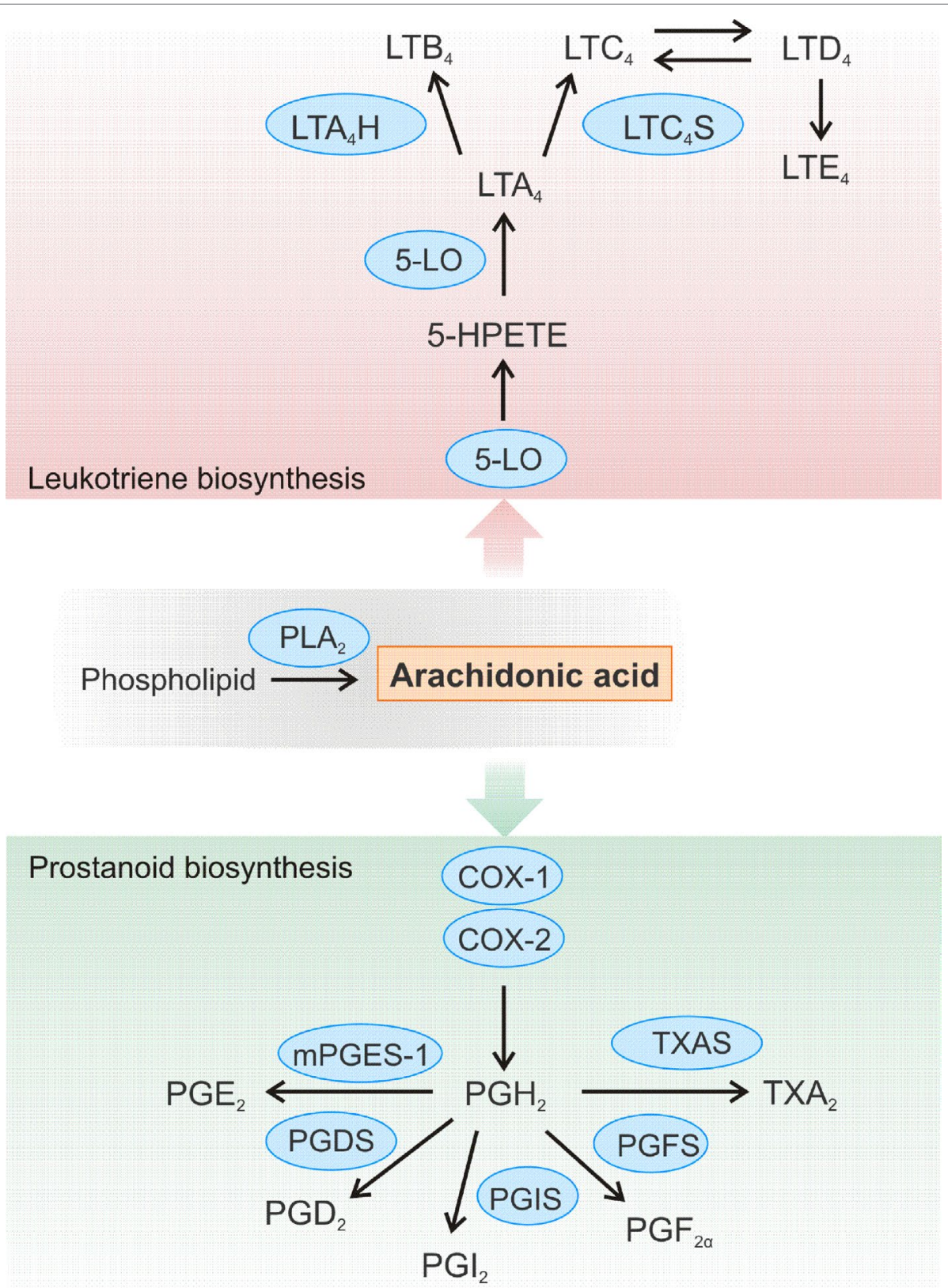

FIGURE 2 | Schematic overview of the leukotriene and prostanoid biosynthesis pathway. Arachidonic acid (AA) is released from cellular membranes by cytosolic phospholipase $A_{2}\left(P L A_{2}\right)$. The free AA can further be converted to different leukotrienes (LT). 5-LO is crucial for the conversion of AA to 5(S)-hydroperoxyeicosatetraenoic acid (5-HPETE) and LTA . LTA $_{4}$ is further converted to LTB $_{4}$ by LTA $A_{4}$ hydrolase $\left(\right.$ LTA $\left._{4} \mathrm{H}\right)$ or to the cysteinyl-containing LTC $\mathrm{L}_{4}$ by $\mathrm{LTC}_{4}$ synthase $\left(\mathrm{LTC}_{4} \mathrm{~S}\right)$, which can be metabolized to $\mathrm{LTD}_{4}$ and $\mathrm{LTE}_{4}$. Biosynthesis of prostanoids begins with the enzyme cyclooxygenase (COX)-1 or COX-2 converting AA to prostaglandin ( $P G) H_{2}$, which is further converted to a variety of other prostanoids. Thromboxane $A_{2}\left(T X A_{2}\right.$ ) is generated by TXA synthase (TXAS), while the synthases PGxS produce the certain PGs: $\mathrm{PGF}_{2 \alpha}, \mathrm{PGl}_{2}$, and $\mathrm{PGD}_{2}$. The microsomal PGE synthase-1 (mPGES-1) catalyzes formation of PGE 2 . 
begins with the release of AA from the cell membrane by phospholipase $\mathrm{A}_{2}$ which is followed by the metabolism of the AA through cyclooxygenases (COXs), lipoxygenases (LOXs), and cytochrome P450 enzymes (Wang and Dubois, 2010). Due to the key role of these enzymes in the formation of bioactive lipid mediators, it is not surprising that 5-LO and COX enzymes are prominent miRNA targets (for previous reviews, see also Ochs et al., 2011; Ochs et al., 2014).

\section{MIRNA REGULATION IN PROSTANOID BIOSYNTHESIS}

The group of prostanoids consists of prostaglandins, thromboxane $\mathrm{A}_{2}$, as well as prostacyclin. Their common denominator is that they can all be formed from AA, which is converted by COX enzymes in a two-step process to $\mathrm{PGH}_{2}$ (Figure 2). This intermediate is then converted to the different prostaglandins by the respective synthases. Prostanoids belong to the most important inflammatory signaling molecules. These lipid mediators exert their multiple biological effects in an autocrine and paracrine manner by binding to their specific cell surface $\mathrm{G}$ protein-coupled receptors. For example, prostaglandin $\mathrm{E}_{2}$ $\left(\mathrm{PGE}_{2}\right)$ is a bioactive lipid that can elicit a wide range of biological effects associated with inflammation and cancer (Jakobsson et al., 1999; Pettersson et al., 2005; Nakanishi and Rosenberg, 2013). It contributes to the development of inflammation and plays a predominant role in promoting cancer progression by induction of cellular proliferation and tumor angiogenesis, inhibition of apoptosis, and suppression of immune responses (Wang and Dubois, 2006; Larsson and Jakobsson, 2015). $\mathrm{PGE}_{2}$ is formed by the conversion of AA to $\mathrm{PGH}_{2}$ by the cyclooxygenases COX-1 or COX-2, followed by processing by PGE synthases, of which microsomal prostaglandin E synthase 1 (mPGES-1) is the key enzyme. The formed $\mathrm{PGE}_{2}$ is then rapidly secreted to act on their specific receptors on recipient cells. These receptors are not only present on immune cells, but also on a variety of cells of the cardiovascular system like cardiomyocytes, smooth muscle cells, or vascular endothelial cells (Suzuki et al., 2011). Thus, $\mathrm{PGE}_{2}$ can be involved in the development of different cardiovascular diseases. It was shown that deletion of mPGES-1 impairs the left ventricular contractile function after acute myocardial infarction and leads to overall remodeling of the left ventricle (Degousee et al., 2008).

\section{Non-Canonical miRNA Regulation of Prostaglandin $\mathrm{E}_{2}$ Biosynthesis}

A variety of cancer types exhibit increased levels of mPGES-1 and its enzymatic product $\mathrm{PGE}_{2}$ - for example, colon (Yoshimatsu et al., 2001b; Wang and Dubois, 2010), prostate (Jain et al., 2008; Hanaka et al., 2009), lung (Yoshimatsu et al., 2001a), and breast cancer (Olesch et al., 2015). Interestingly, there were marked differences in the extent of upregulation of mPGES- 1 and $\mathrm{PGE}_{2}$ in individual lung tumors (Yoshimatsu et al., 2001a; Wu et al., 2010). This effect can be attributed to individual expression variations of COX-2 and mPGES-1 (Wang et al., 2006; Hughes et al., 2008).
However, the observed variability cannot be explained solely by different transcriptional regulation mechanisms [such as nuclear factor $\kappa \mathrm{B}(\mathrm{NF \kappa B})$ ] (Yamamoto et al., 1995; Kang et al., 2007), suggesting that additional—namely, post-transcriptional mechanisms - might be involved - for instance, miRNA regulation.

Recently, we demonstrated that miR-574-5p activates mPGES1-derived $\mathrm{PGE}_{2}$ synthesis in human non-small cell lung cancer (NSCLC). Moreover, this miRNA promotes tumor growth in vivo, which is completely blocked by the administration of the mPGES-1 inhibitor CIII (Leclerc et al., 2013). Mechanistically, it could be shown that miR-574-5p acts as RNA decoy to CUGRNA-binding protein 1 (CUGBP1) (Figures 1C, 3A) and that it antagonizes the CUGBP1 function as a post-transcriptional regulator (Mukhopadhyay et al., 2003; Subbaramaiah et al., 2003; Gao et al., 2015). In human, NSCLC as well as under inflammatory conditions, miR-574-5p is strongly upregulated and induces mPGES-1 expression by preventing CUGBP1 binding to the mPGES-1-3'UTR. This leads to an enhanced alternative splicing and the generation of a $3^{\prime}$ UTR splice variant. Importantly, the nuclear localization of miR-574-5p and CUGBP1 is in line with its regulatory function on mPGES-1 mRNA splicing (Saul et al., 2019). The newly discovered association between miR-574-5p overexpression and $\mathrm{PGE}_{2}$-mediated growth of lung cancer cells in vivo suggests that pharmacological inhibition of $\mathrm{PGE}_{2}$ formation with mPGES-1 or COX inhibitors might be of considerable therapeutic value for NSCLC patients with high miR-574-5p levels (Saul et al., 2019). In this respect, mPGES-1 inhibition might be of particular interest since inhibition of mPGES-1, instead of COX-2, may be associated with fewer side effects as other prostanoids would not be affected.

\section{Canonical miRNA Regulation of Prostaglandin Biosynthesis}

There are two known isoenzymes responsible for the generation of prostanoids: cyclooxygenase-1 (COX-1) and cyclooxygenase-2 (COX-2), both of which catalyze the same enzymatic reaction. COX-1 represents a housekeeping enzyme responsible for maintaining basal prostanoid levels, which are important for tissue homeostasis. In contrast, COX-2 is barely detectable in most normal tissues, but is strongly induced in response to inflammatory cytokines, hypoxia, and other stressors (Samuelsson et al., 2007; Wang and Dubois, 2010).

COX-2 expression is regulated at different levels (Dixon et al., 2000; Harper and Tyson-Capper, 2008). Various transcription factors such as NFkB, activator protein 1 (AP1), or the cAMP-responsive element-binding protein (CREB) are involved in its transcriptional regulation (Yamamoto et al., 1995; Kang et al., 2007).

At the post-transcriptional level, COX-2 expression is regulated by mRNA stability and translation efficiency mostly including trans- and cis-acting factors (Dixon et al., 2000; Young and Dixon, 2010). For example, RNA-binding proteins can interact with AU-rich elements (AREs) within the COX-2 3'UTR like CUG triplet repeat-RNA-binding protein 2 (CUGBP2) (Mukhopadhyay et al., 2003) or the mRNAstability factor HuR (Erkinheimo et al., 2003; Subbaramaiah 

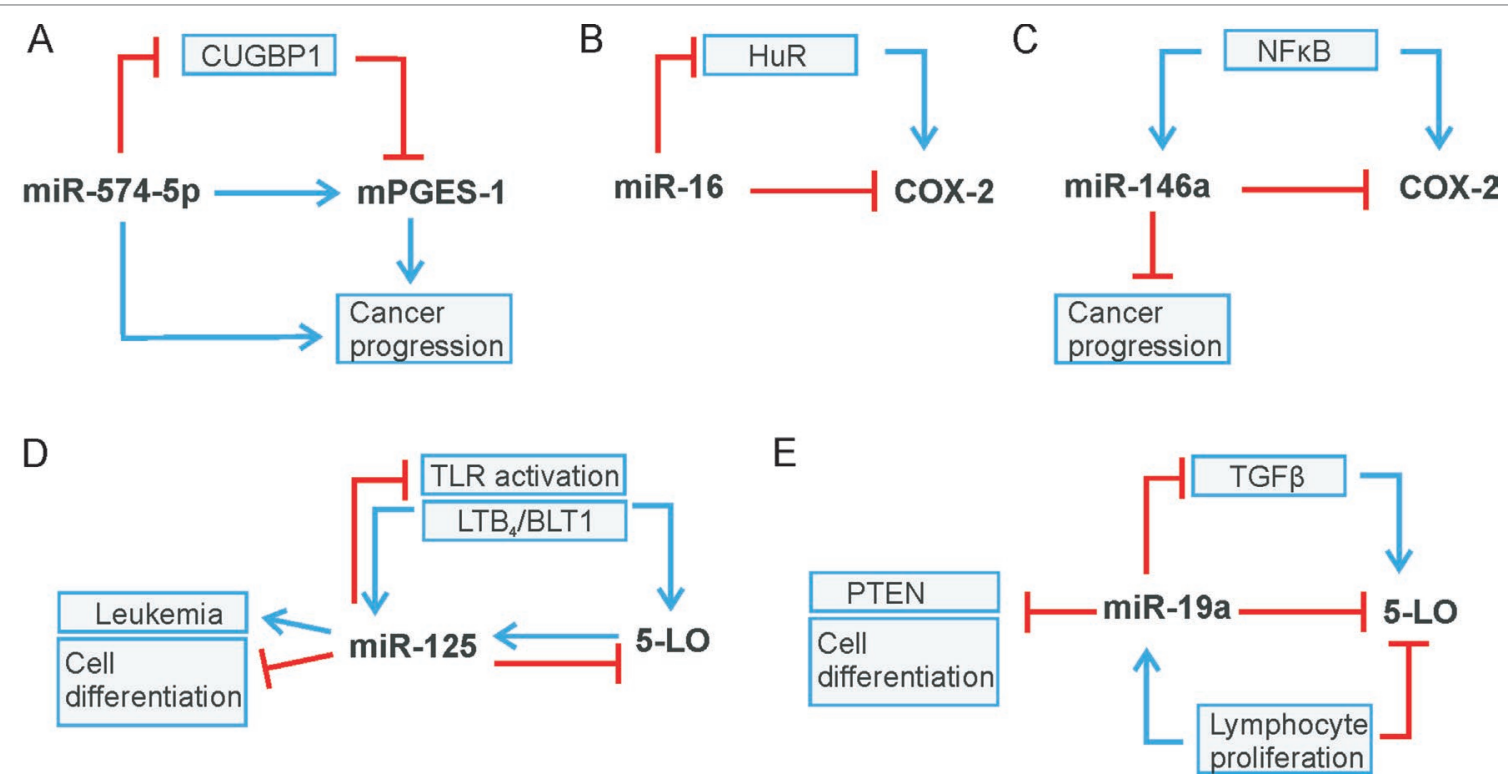

FIGURE 3 | Regulatory circuits of leukotriene and prostaglandin biosynthesis. (A) miR-574-5p/CUGBP1 regulates mPGES-1 level, (B) miR-16/HuR and (C) miR-146a modulate COX-2 expression. (D) miR-125 and (E) miR-19a regulate 5-LO level. Stimulation is indicated by blue arrows, whereas red lines indicate inhibition.

et al., 2003). Tristetraprolin (TTP), another RNA-binding protein that promotes mRNA instability, has been shown to bind to the 3 'UTR of COX-2 and thus contributes to the posttranscriptional regulation of COX-2 (Sawaoka et al., 2003). In addition, the use of an alternative polyadenylation signal may regulate COX-2 mRNA stability and translation (Hall-Pogar et al., 2005; Hall-Pogar et al., 2007).

In recent years, miRNAs have been identified as additional players in the post-transcriptional control of COX-2 expression (see Table 1). Interestingly, miR-16 is complementary to sequences in the AU-rich regions of the COX-2 3'UTR, which allows direct binding of miR-16, and in turn, alters COX-2 mRNA stability (Jing et al., 2005) (Figure 3). In association with TTP, miR-16 can promote mRNA decay. However, TTP does not bind directly to miR-16 but interacts through the association with RISC components to form a complex with miR-16 and promote mRNA degradation (Jing et al., 2005). Furthermore, miR-16 silences COX-2 expression in hepatoma cells via two mechanisms: by binding directly to the COX-2 3 '-UTR and by decreasing the levels of the RNA-binding protein HuR (Agra Andrieu et al., 2012) (Figure 3B). MiR-16 also competes with the RNA-binding protein heterogeneous nuclear ribonuclear protein $\mathrm{K}$ (hnRNP $\mathrm{K}$ ) for binding to COX-2 3'UTR and thus modulates COX-2 expression on the post-transcriptional level (Shanmugam et al., 2008).

In addition, a considerable number of reports focus on miR-144, which directly targets COX-2 mRNA to downregulate its protein level. For example, the balance between miR-144, COX-2, and c-fos regulates $\mathrm{PGE}_{2}$ synthesis in the amnion of pregnant humans and mice. The amnion is the major source of $\mathrm{PGE}_{2}$ and plays a central role in the process of premature labor. The transcription factor c-fos induces expression of COX-2 and miR-144. The latter in turn generates a negative feedback loop by directly and indirectly inhibiting both COX-2 and c-fos. This inhibition has a negative effect on $\mathrm{PGE}_{2}$ generation and thus prevents premature contractions ( $\mathrm{Li}$ et al., 2016). A negative correlation of miR-144-5p and COX-2 was also observed in human inflamed gingival tissue from periodontitis patients (Li et al., 2019). Moreover, a significant downregulation of miR-144 and miR-26a compared to healthy surrounding tissue was found in the tumor tissue of patients with esophageal squamous cell carcinoma (ESCC). The two miRNAs were confirmed to bind to COX-2 mRNA, thus downregulating the protein level of COX-2. It has been shown that, due to downregulation of miR-144 and miR-26a in tumor tissue, COX-2 activity significantly increased and subsequently promoted cell proliferation and metastasis (Shao et al., 2016). COX-2 is also a canonical target of miR-101-3p that is downregulated in ESCC cells stimulated with cigarette smoking extract (CSE). It has been shown that the promoting effect of CSE on ESCC is due to COX-2 upregulation. It was further demonstrated that the mechanism by which CSE regulates COX-2 expression is mediated by miR101-3p to promote cell proliferation (Gong et al., 2016). Another miRNA that regulates COX-2 via its canonical function is miR146a, a miRNA that is regulated like COX-2 by NFkB signaling (Poligone and Baldwin, 2001; Taganov et al., 2006). In human lung cancer, miR-146a directly regulates COX-2 mRNA and thus the protein level of COX-2 in lung cancer cells (Cornett and Lutz, 2014) (Figure 3C). In human fibroblasts of smokers with chronic obstructive pulmonary disease, it was found that single nucleotide polymorphisms in the miR-146a precursor caused several patients to have reduced miRNA level, which significantly improved baseline lung function (Wang et al., 2015). Very recently, it was demonstrated that the polymorphisms of miR-146a (rs2910164) and plasmacytoma variant translocation 1 (PVT1; rs13281615) affect the prognosis of colon cancer by regulating COX-2 
TABLE 1 | Summary - miRNAs influencing the prostaglandin pathway by binding to mRNAs of key enzymes or interfering with RNA-binding protein CUGBP1 (see mPGES-1)

\begin{tabular}{|c|c|c|c|}
\hline miRNA & Target & Tissue/disease & Reference \\
\hline Hsa-miR-144 & COX-2 & Premature labor & (Li et al., 2016) \\
\hline Hsa-miR-144-5p & COX-2 & Periodontitis & (Li et al., 2019) \\
\hline Hsa-miR-144 & cox-2 & Esophageal squamous cell cancer & (Shao et al., 2016) \\
\hline \multicolumn{4}{|l|}{ Hsa-miR-26a } \\
\hline Hsa-miR-26b & coX-2 & Nasopharyngeal epithelial cancer & (Ji et al., 2010) \\
\hline Hsa-miR-26b & COX-2 & Oral lichen planus & (Danielsson et al., 2012) \\
\hline Hsa-miR-26b & coX-2 & Breast cancer & (Li et al., 2013) \\
\hline Hsa-miR-216a-3p & cox-2 & Colorectal cancer & (Wang et al., 2018) \\
\hline Hsa-miR-30a & cox-2 & Gastric cancer & (Liu et al., 2017) \\
\hline Hsa-miR-146a & mPGES-2 & $\begin{array}{l}\text { Bone marrow-derived mesenchymal } \\
\text { stem cells }\end{array}$ & (Matysiak et al., 2013) \\
\hline Hsa-miR-146a & COX-2 & COPD & (Sato et al., 2010) \\
\hline Hsa-miR-146a & $\mathrm{COX}-2$ & Astrocytes & (lyer et al., 2012) \\
\hline Hsa-miR-146a & cox-2 & Colon cancer & (Zhang et al., 2019) \\
\hline Hsa-miR-146a & COX-2 & Lung cancer & (Cornett and Lutz, 2014) \\
\hline Hsa-miR-146a & cox-2 & COPD & (Wang et al., 2015) \\
\hline Mmu-miR-199a & cox-2 & Mouse uterus, endometrial cancer & (Chakrabarty et al., 2007; Daikoku \\
\hline Mmu-miR-101a & & & et al., 2008) \\
\hline Hsa-miR-101 & COX-2 & Colon cancer & (Strillacci et al., 2009) \\
\hline Hsa-miR-101 & COX-2 & Endometrial serous carcinoma & (Hiroki et al., 2010) \\
\hline Hsa-miR-101a & COX-2 & Mammary gland & (Tanaka et al., 2009) \\
\hline Hsa-miR-101 & COX-2 & Gastric cancer & (He et al., 2012) \\
\hline Hsa-miR-101 & cox-2 & Prostate cancer & (Hao et al., 2011) \\
\hline Hsa-miR-101-3p & cox-2 & Esophageal squamous cell cancer & (Gong et al., 2016) \\
\hline Hsa-miR-16 & cox-2 & Cervical cancer & (Jing et al., 2005) \\
\hline Hsa-miR-16 & COX-2 & Hepatocellular carcinoma & (Agra Andrieu et al., 2012) \\
\hline Hsa-miR-16 & COX-2 & Monocytes (THP-1 cells) & (Shanmugam et al., 2008) \\
\hline Hsa-miR-137 & COX-2 & Glioma & (Chen et al., 2012) \\
\hline Hsa-miR-143 & cox-2 & Amnion mesenchymal cells & (Kim et al., 2011) \\
\hline Hsa-miR-542-3p & cox-2 & Colon cancer & (Moore et al., 2012) \\
\hline Hsa-miR-574-5p & mPGES-1 & Lung cancer (NSCLC) & (Saul et al., 2019) \\
\hline Hsa-miR-21 & 15-PGDH & Cholangiocarcinoma & (Lu et al., 2014) \\
\hline Hsa-miR-21 & 15-PGDH & Tongue squamous cell cancer & (He et al., 2016) \\
\hline Hsa-miR-21 & 15-PGDH & Gastric cancer & (Li et al., 2019) \\
\hline Hsa-miR-21 & 15-PGDH & Colon cancer & (Monteleone et al., 2019) \\
\hline Hsa-miR-26a/b & 15-PGDH & Cholangiocarcinoma & (Yao et al., 2015) \\
\hline Hsa-miR-620 & 15-PGDH & $\begin{array}{l}\text { Prostate adenocarcinoma cell line } \\
\text { (DU145); breast cancer cell line } \\
\text { (MDA-MB-231) }\end{array}$ & (Huang et al., 2015) \\
\hline Hsa-miR-218 & 15-PGDH & $\begin{array}{l}\text { Synovial mesenchymal stem cells } \\
\text { (SMSCs) }\end{array}$ & (Cong et al., 2017) \\
\hline Hsa-miR146b-3p & 15-PGDH & Cervical cancer & (Yao et al., 2018) \\
\hline
\end{tabular}

expression and cell apoptosis. The presence of PVT1 decreased the expression level of miR-146a, which in turn increased the COX-2 level (Zhang et al., 2019). Another miRNA that suppresses inflammation-related tumors is miR-30a. MiR-30a is crucial for regulation of growth and migration of Heliobacter pylori-infected gastric cancer via targeting COX-2 and B cell CLL/lymphoma 9 (BCL 9) (Liu et al., 2017). In the same way, colorectal cancer is influenced by miR-216a-3p, which directly targets COX-2 via its canonical function (Wang et al., 2018).

In addition to the miRNA regulation of enzymes involved in $\mathrm{PGE}_{2}$ formation like COX-2 and mPGES-1, it is important to explore how the $\mathrm{PGE}_{2}$-metabolizing enzyme is regulated by miRs. The key enzyme that converts $\mathrm{PGE}_{2}$ to its biologically inactive metabolite is the $\mathrm{NAD}^{+}$-dependent 15-hydroxyprostaglandin dehydrogenase (15-PGDH/HPGD) (Ensor and Tai, 1995). In cholangiocarcinoma cells, 15-PGDH was identified as a direct target of miR-21. In addition, COX-2 overexpression and $\mathrm{PGE}_{2}$ treatment increase the level of miR-21 associated with enhanced miR-21 promoter activity (Lu et al., 2014). The finding that miR-21 directly regulates 15-PDGH was further confirmed by recent publications on tongue squamous cell carcinoma (He et al., 2016), gastric cancer (Li et al., 2019) and colon cancer (Monteleone et al., 2019). Interestingly, epithelial growth factor (EGF) signaling in colorectal cancer cells reduces the level of 15-PGDH and simultaneously increases the miR-21 level (Monteleone et al., 2019).

In addition to this, other miRNAs are known to modulate 15-PGDH expression. Omega-3 polyunsaturated fatty acids ( $\omega-3$ PUFA) upregulate 15-PGDH expression by inhibiting miR-26a and miR-26b. This directly contributes to $\omega-3$ PUFA-induced inhibition of human cholangiocarcinoma cell growth, providing 
a preclinical justification for the evaluation of $\omega-3$ PUFA in the treatment of cholangiocarcinoma (Yao et al., 2015). MiR620 directly targets $15-\mathrm{PGDH}$, which results in an increase in $\mathrm{PGE}_{2}$ promoting radioresistance in cancer cells like the human prostate adenocarcinoma cell line DU145 and the breast cancer cell line MDA-MB-231 (Huang et al., 2015). Furthermore, miR218 directly regulates the expression level of 15-PGDH during differentiation of synovial mesenchymal stem cells (SMSCs) into cartilage and subsequently inhibits osteogenesis during chondrogenesis (Cong et al., 2017). Finally, 15-PDGH was identified as the canonical target of miR-146b-3p that promotes proliferation, migration, and anchorage-independent growth of cervical cancer cells (Yao et al., 2018).

\section{Influence of the Prostaglandin Pathway on miRNA Expression}

In addition to the regulation of the enzymes of the prostaglandin pathway by miRNAs, the influence of prostaglandin signaling on miRNA expression has also been investigated. It was found that COX-2 signaling increases the oncogenic miR-526b and miR655 levels in human breast cancer by activating the EP4 receptor. Thus, COX-2 signaling strongly influences the phenotype of the tumor by promoting cellular migration, invasion, or proliferation (Majumder et al., 2015; Majumder et al., 2018).

In addition, it was found that cancer-associated fibroblasts (CAFs) develop a senescence-associated secretory phenotype (SASP) that contributes to cancer progression. Interestingly, senescent CAFs have increased levels of $\mathrm{PGE}_{2}$ and COX-2. Moreover, miR-335 is upregulated in the senescent normal fibroblasts as well as CAFs. This modulates the secretion of SASP factors and induces the mobility of cancer cells in co-cultures, at least partially by suppressing the expression of the phosphatase and tensin homologue (PTEN). With the application of the COX-2 inhibitor celecoxib, expression of miR-335 was strongly reduced, suggesting a new miR-335/COX-2/PTEN axis that modulates the inflammasome in senescent fibroblasts (Kabir et al., 2016).

In line with these results, it was demonstrated that the mPGES-1/PGE 2 pathway affects the expression level of miR$15 \mathrm{a}$ and miR-186 in prostate cancer. High $\mathrm{PGE}_{2}$ levels reduced Dicer expression and consequently miRNA biogenesis in prostate cancer cells. It is noteworthy that $\mathrm{PGE}_{2}$-mediated downregulation of miR-15a and miR-186 is directly associated to vascular endothelial growth factor (VEGF) expression and angiogenesis. This suggests that these miRNAs may be potential candidates for mitigating the aggressive properties of prostate cancer. This alternative approach could overcome the chemoresistance, which is common for drugs targeting VEGF and/or VEGF receptors (Terzuoli et al., 2016).

\section{MIRNA REGULATION IN LEUKOTRIENE BIOSYNTHESIS}

The 5-lipoxygenase (5-LO) is the key enzyme of the leukotriene pathway. It interacts with the 5-LO-activating protein (FLAP) and catalyzestheconversion of AA into 5(S)-hydroperoxyeicosatetraenoic acid (5-HPETE) and leukotriene (LT) $\mathrm{A}_{4}$. The $\mathrm{LTA}_{4}$ is then subsequently converted either into biologically active $\mathrm{LTB}_{4}$ by $\mathrm{LTA}_{4}$ hydrolase or into $\mathrm{LTC}_{4}$ by $\mathrm{LTC}_{4}$ synthase and the $\mathrm{LTC}_{4}$ synthase isoenzyme MGST2. Over the last decades, different studies have shown that 5-LO-derived AA metabolites play an important role in inflammatory reactions like inflammatory disorders and allergic diseases such as asthma, allergic rhinitis, cardiovascular diseases, as well as in different types of cancer (Steinhilber and Hofmann, 2014).

\section{Canonical miRNA Regulation on Leukotriene Pathway}

In contrast to COX-2, the knowledge about post-transcriptional regulation of 5-LO is rather limited. It is known that the combination of alternative splicing and RNA decay modulates 5-LO gene expression (Ochs et al., 2012). Furthermore, several publications demonstrated that 5-LO is a canonical target for miR-19a-3p, miR125-5p (Busch et al., 2015), miR-216-3p (Wang et al., 2018), and miR-674-5p (Su et al., 2016) (see Table 2). Specifically, miR-19a-3p and miR-125-5p regulate 5-LO expression in the human myeloid cell line MonoMac 6. In contrast, only miR-19a-3p modulates the 5-LO protein level in human T-lymphocytes stimulated with phytohemagglutinin (PHA). Overall, it reveals that miR-19a-3p and miR-125b-5p target 5-LO in a cell type and stimulus-specific manner (Busch et al., 2015). Interestingly, miR-125 and miR-19a seem to be parts of regulatory circuit-controlling immune reactions and cell proliferation (Figures 3D, E). 5-LO expression is induced by TLR/NFkB activation (Lee et al., 2015) or during cell stimulation by transforming growth factor (TGF)- $\beta$ (Steinhilber et al., 1993). The same signals were also reported to induce miR-125 (Curtale et al., 2018; Hildebrand et al., 2018) as well as miR-19a, which in turn downregulates components of NFkB or TGF- $\beta$ signaling, respectively, and also 5-LO (Figures 3D, E) (Dews et al., 2010; Busch

TABLE 2 | Summary - miRNAs influencing the leukotriene pathway by binding to mRNAs of key enzymes.

\begin{tabular}{lcll}
\hline miRNA & Target & \multicolumn{1}{c}{ Tissue/disease } & Reference \\
\hline Hsa-miR-19a-3p & $5-$ LO & Monocytes (MM6 cells), & (Busch et al., 2015) \\
Hsa-miR-125-5p & & T-lymphocytes & (Su et al., 2016) \\
Hsa-miR-674-5p & $5-$ LO & Acute mouse liver injury & (Wang et al., 2018) \\
Hsa-miR-216a-3p & $5-$-O & Colorectal cancer & (lacona et al., 2018) \\
Hsa-miR-146a & FLAP & Lung cancer & (Gonsalves and Kalra, 2010) \\
Hsa-miR-135a & FLAP & Pulmonary microvascular & endothelial cells
\end{tabular}


et al., 2015). Thus, upregulation of miR-19a and downregulation of 5-LO expression are associated with cell proliferation in T-lymphocytes (Busch et al., 2015). Furthermore, it is well known that upregulation of miR-19a inhibits cell differentiation and promotes cell growth and cancer development-for instance, by suppression of PTEN (Lewis et al., 2003). MiR-674-5p was identified as a direct regulator of 5-LO mRNA in mice. It is further discussed as a negative regulator in 5-LO-mediated autoimmune diseases of the liver, thus representing a promising approach to future therapeutic measures (Su et al., 2016). Recently, it was shown that miR-216a-3p regulates not only COX-2 but also 5-LO expression in colon cancer, thus affecting colon cancer cell proliferation. These data indicate that miR-216-3p might represent a novel target for colorectal cancer treatment (Wang et al., 2018). Interestingly, not only 5-LO but also FLAP is targeted by miRs, like miR-146a in human lung cancer (Iacona et al., 2018). Moreover, miR-146a is also known to regulate COX-2 expression in lung cancer (Cornett and Lutz, 2014), which indicates a role of miR-146a as an endogenous dual inhibitor of AA metabolism in lung cancer by regulating prostaglandins and LTs, similar to miR-216a-3p (Iacona et al., 2018).

\section{Influence of the Leukotriene Pathway on miRNA Expression}

It is well known that 5-LO interacts with the C-terminal domain of human Dicer. The interaction between 5-LO and Dicer leads to an enhanced 5-LO enzymatic activity as well as Dicer activity in vitro. These results suggest that the processing of specific miRNAs by Dicer might be regulated by the 5-LO/Dicer interaction (DincbasRenqvist et al., 2009). In addition to the direct 5-LO/Dicer interaction, 5-LO products can also modulate miRNA expression. Thus, $\mathrm{LTB}_{4}$ induces the expression of inflammatory miRNAs including miR-155, miR-146a and miR125b in macrophages via the LT B4 receptor-1 (BLT1) and Ga1 signaling (Wang et al., 2014).

\section{CONCLUSIONS}

The number of miRNAs that were discovered in recent years to be involved in the regulation of the expression of key enzymes in

\section{REFERENCES}

Agra Andrieu, N., Motino, O., Mayoral, R., Llorente Izquierdo, C., Fernandez-Alvarez, A., Bosca, L., et al. (2012). Cyclooxygenase-2 is a target of microRNA-16 in human hepatoma cells. PLoS One 7, e50935. doi: 10.1371/journal.pone.0050935

Busch, S., Auth, E., Scholl, F., Huenecke, S., Koehl, U., Suess, B., et al. (2015). 5-lipoxygenase is a direct target of miR-19a-3p and miR-125b-5p. J. Immunol. 194, 1646-1653. doi: 10.4049/jimmunol.1402163

Chakrabarty, A., Tranguch, S., Daikoku, T., Jensen, K., Furneaux, H., and Dey, S. K. (2007). MicroRNA regulation of cyclooxygenase-2 during embryo implantation. Proc. Natl. Acad. Sci. U. S. A. 104, 15144-15149. doi: 10.1073/pnas.0705917104

Chen, L., Wang, X., Wang, H., Li, Y., Yan, W., Han, L., et al. (2012). miR-137 is frequently down-regulated in glioblastoma and is a negative regulator of Cox2. Eur. J. Cancer 48, 3104-3111. doi: 10.1016/j.ejca.2012.02.007

Cong, R., Tao, K., Fu, P., Lou, L., Zhu, Y., Chen, S., et al. (2017). MicroRNA218 promotes prostaglandin E2 to inhibit osteogenic differentiation in synovial mesenchymal stem cells by targeting 15hydroxyprostaglandin dehydrogenase [NAD(+)]. Mol. Med. Rep. 16, 9347-9354. doi: 10.3892/mmr.2017.7795 prostanoid and LT biosynthesis is steadily increasing. Tables 1, 2 give a comprehensive overview of all currently known miRNAs involved in inflammatory processes. There is growing evidence that many of these miRNAs are involved in complex regulatory cascades and networks with multiple layers of integrated signals and feedback loops required for fine-tuning of biological functions such as inflammatory responses or cell growth. Besides the direct, canonical regulation of mRNA stability and translation of enzymes of the AA cascade by miRNAs, it was found that miRNAs that interfere with HUR or TTP function are involved in the regulation of COX-2 expression. Furthermore, a novel non-canonical mechanism was found for miR-574-5p, which acts as a decoy for CUGBP1 and strongly stimulates $\mathrm{PGE}_{2}$ formation. It becomes clear that miRNAs can also be packed into EVs so that they are involved in cell-cell communication. This suggests that miRNAs not only regulate cellular functions in an autocrine/intracrine manner but also can affect processes such as the formation of lipid mediators in a paracrine fashion. Of note, 5-LO was identified as a binding protein for Dicer, which suggests that 5 -LO can modulate the Dicer function and interferes with miRNA generation. Thus, it becomes increasingly clear that there are multiple links between the miRNA network and lipid signaling. The progress in the understanding of these interactions will help to develop new therapeutic strategies for the treatment of inflammatory diseases and cancer.

\section{AUTHOR CONTRIBUTIONS}

MS wrote the manuscript. AE, DS, and BS contributed to writing and editing the manuscript.

\section{FUNDING}

This project was supported by the Else Kröner-Fresenius Stiftung (Else Kröner-Fresenius-Graduiertenkolleg), the Deutsche Forschungsgemeinschaft (SFB902 and ECCPS), Athene Young Investigator program (Technische Universität Darmstadt; grant no: n/a), and BMBF (KMU-innovativ-22: miRTumorProst; 031B0768B).

Cornett, A. L., and Lutz, C. S. (2014). Regulation of COX-2 expression by miR146a in lung cancer cells. RNA 20, 1419-1430. doi: 10.1261/rna.044149.113

Croce, C. M. (2009). Causes and consequences of microRNA dysregulation in cancer. Nat. Rev. Genet. 10, 704-714. doi: 10.1038/nrg2634

Curtale, G., Renzi, T. A., Mirolo, M., Drufuca, L., Albanese, M., De Luca, M., et al. (2018). Multi-step regulation of the TLR4 pathway by the miR-125a 99b let-7e Cluster. Front. Immunol. 9, 2037. doi: 10.3389/fimmu.2018.02037

Daikoku, T., Hirota, Y., Tranguch, S., Joshi, A. R., Demayo, F. J., Lydon, J. P., et al. (2008). Conditional loss of uterine Pten unfailingly and rapidly induces endometrial cancer in mice. Cancer Res. 68, 5619-5627. doi: 10.1158/00085472.CAN-08-1274

Danielsson, K., Ebrahimi, M., Wahlin, Y. B., Nylander, K., and Boldrup, L. (2012). Increased levels of COX-2 in oral lichen planus supports an autoimmune cause of the disease. J. Eur. Acad. Dermatol. Venereol. 26, 1415-1419. doi: 10.1111/j.1468-3083.2011.04306.x

De Rie, D., Abugessaisa, I., Alam, T., Arner, E., Arner, P., Ashoor, H., et al. (2017). An integrated expression atlas of miRNAs and their promoters in human and mouse. Nat. Biotechnol. 35, 872-878. doi: 10.1038/nbt.3947 
Degousee, N., Fazel, S., Angoulvant, D., Stefanski, E., Pawelzik, S. C., Korotkova, M., et al. (2008). Microsomal prostaglandin E2 synthase-1 deletion leads to adverse left ventricular remodeling after myocardial infarction. Circulation 117, 17011710. doi: 10.1161/CIRCULATIONAHA.107.749739

Dews, M., Fox, J. L., Hultine, S., Sundaram, P., Wang, W., Liu, Y. Y., et al. (2010). The myc-miR-17 92 axis blunts TGF beta\} signaling and production of multiple TGF \{beta\}-dependent antiangiogenic factors. Cancer Res. 70, 8233-8246. doi: 10.1158/0008-5472.CAN-10-2412

Dincbas-Renqvist, V., Pepin, G., Rakonjac, M., Plante, I., Ouellet, D. L., Hermansson, A., et al. (2009). Human Dicer C-terminus functions as a 5-lipoxygenase binding domain. Biochim. Biophys. Acta 1789, 99-108. doi: 10.1016/j.bbagrm.2008.10.002

Dixon, D. A., Kaplan, C. D., Mcintyre, T. M., Zimmerman, G. A., and Prescott, S. M. (2000). Post-transcriptional control of cyclooxygenase-2 gene expression. The role of the 3'-untranslated region. J. Biol. Chem. 275, 11750-11757. doi: $10.1074 / \mathrm{jbc} .275 .16 .11750$

Eiring, A. M., Harb, J. G., Neviani, P., Garton, C., Oaks, J. J., Spizzo, R., et al. (2010). miR-328 functions as an RNA decoy to modulate hnRNP E2 regulation of mRNA translation in leukemic blasts. Cell 140, 652-665. doi: 10.1016/j. cell.2010.01.007

Ensor, C. M., and Tai, H. H. (1995). 15-Hydroxyprostaglandin dehydrogenase. J. Lipid Mediat. Cell Signal 12, 313-319. doi: 10.1016/0929-7855(95)00040-W

Erkinheimo, T. L., Lassus, H., Sivula, A., Sengupta, S., Furneaux, H., Hla, T., et al. (2003). Cytoplasmic HuR expression correlates with poor outcome and with cyclooxygenase 2 expression in serous ovarian carcinoma. Cancer Res. 63, 7591-7594.

Fabbri, M., Paone, A., Calore, F., Galli, R., Gaudio, E., Santhanam, R., et al. (2012). MicroRNAs bind to toll-like receptors to induce prometastatic inflammatory response. Proc. Natl. Acad. Sci. U. S. A. 109, E2110-E2116. doi: 10.1073/ pnas. 1209414109

Filipowicz, W., Bhattacharyya, S. N., and Sonenberg, N. (2008). Mechanisms of post-transcriptional regulation by microRNAs: are the answers in sight? Nat. Rev. Genet. 9, 102-114. doi: 10.1038/nrg2290

Gao, C., Yu, Z., Liu, S., Xin, H., and Li, X. (2015). Overexpression of CUGBP1 is associated with the progression of non-small cell lung cancer. Tumour Biol. 36 (6), 4583-4589. doi: 10.1007/s13277-015-3103-1

Garzon, R., Fabbri, M., Cimmino, A., Calin, G. A., and Croce, C. M. (2006). MicroRNA expression and function in cancer. Trends Mol. Med. 12, 580-587. doi: 10.1016/j.molmed.2006.10.006

Goldie, B. J., Dun, M. D., Lin, M., Smith, N. D., Verrills, N. M., Dayas, C. V., et al. (2014). Activity-associated miRNA are packaged in Map1b-enriched exosomes released from depolarized neurons. Nucleic Acids Res. 42, 9195-9208. doi: 10.1093/nar/gku594

Gong, J., Chu, Y., Xu, M., Huo, J., and Lv, L. (2016). Esophageal squamous cell carcinoma cell proliferation induced by exposure to low concentration of cigarette smoke extract is mediated via targeting miR-101-3p/COX-2 pathway. Oncol. Rep. 35, 463-471. doi: 10.3892/or.2015.4379

Gonsalves, C. S., and Kalra, V. K. (2010). Hypoxia-mediated expression of 5-lipoxygenase-activating protein involves HIF-1alpha and NF-kappaB and microRNAs 135a and 199a-5p. J. Immunol. 184, 3878-3888. doi: 10.4049/ jimmunol.0902594

Hall-Pogar, T., Liang, S., Hague, L. K., and Lutz, C. S. (2007). Specific trans-acting proteins interact with auxiliary RNA polyadenylation elements in the COX-2 3'-UTR. RNA 13, 1103-1115. doi: 10.1261/rna.577707

Hall-Pogar, T., Zhang, H., Tian, B., and Lutz, C. S. (2005). Alternative polyadenylation of cyclooxygenase-2. Nucleic Acids Res. 33, 2565-2579. doi: 10.1093/nar/gki544

Hanaka, H., Pawelzik, S. C., Johnsen, J. I., Rakonjac, M., Terawaki, K., Rasmuson, A., et al. (2009). Microsomal prostaglandin E synthase 1 determines tumor growth in vivo of prostate and lung cancer cells. Proc. Natl. Acad. Sci. U. S. A. 106, 18757-18762. doi: 10.1073/pnas.0910218106

Hao, Y., Gu, X., Zhao, Y., Greene, S., Sha, W., Smoot, D. T., et al. (2011). Enforced expression of miR-101 inhibits prostate cancer cell growth by modulating the COX-2 pathway in vivo. Cancer Prev. Res. (Phila) 4, 1073-1083. doi: 10.1158/1940-6207.CAPR-10-0333

Harper, K. A., and Tyson-Capper, A. J. (2008). Complexity of COX-2 gene regulation. Biochem. Soc. Trans. 36, 543-545. doi: 10.1042/BST0360543
He, Q., Chen, Z., Dong, Q., Zhang, L., Chen, D., Patel, A., et al. (2016). MicroRNA-21 regulates prostaglandin E2 signaling pathway by targeting 15-hydroxyprostaglandin dehydrogenase in tongue squamous cell carcinoma. BMC Cancer 16, 685. doi: 10.1186/s12885-016-2716-0

He, X. P., Shao, Y., Li, X. L., Xu, W., Chen, G. S., Sun, H. H., et al. (2012). Downregulation of miR-101 in gastric cancer correlates with cyclooxygenase-2 overexpression and tumor growth. FEBS J. 279, 4201-4212. doi: 10.1111/febs.12013

Hildebrand, D., Eberle, M. E., Wolfle, S. M., Egler, F., Sahin, D., Sahr, A., et al. (2018). Hsa-miR-99b/let-7e/miR-125a cluster regulates pathogen recognition receptor-stimulated suppressive antigen-presenting cells. Front. Immunol. 9, 1224. doi: $10.3389 /$ fimmu.2018.01224

Hiroki, E., Akahira, J., Suzuki, F., Nagase, S., Ito, K., Suzuki, T., et al. (2010). Changes in microRNA expression levels correlate with clinicopathological features and prognoses in endometrial serous adenocarcinomas. Cancer Sci. 101, 241-249. doi: 10.1111/j.1349-7006.2009.01385.x

Huang, X., Taeb, S., Jahangiri, S., Korpela, E., Cadonic, I., Yu, N., et al. (2015). miR620 promotes tumor radioresistance by targeting 15-hydroxyprostaglandin dehydrogenase (HPGD). Oncotarget 6, 22439-22451. doi: 10.18632/ oncotarget. 4210

Hughes, D., Otani, T., Yang, P., Newman, R. A., Yantiss, R. K., Altorki, N. K., et al. (2008). NAD+-dependent 15-hydroxyprostaglandin dehydrogenase regulates levels of bioactive lipids in non-small cell lung cancer. Cancer Prev. Res. (Phila) 1, 241-249. doi: 10.1158/1940-6207.CAPR-08-0055

Iacona, J. R., Monteleone, N. J., and Lutz, C. S. (2018). miR-146a suppresses 5-lipoxygenase activating protein (FLAP) expression and Leukotriene B4 production in lung cancer cells. Oncotarget 9, 26751-26769. doi: 10.18632/ oncotarget.25482

Iyer, A., Zurolo, E., Prabowo, A., Fluiter, K., Spliet, W. G., Van Rijen, P. C., et al. (2012). MicroRNA-146a: a key regulator of astrocyte-mediated inflammatory response. PLoS One 7, e44789. doi: 10.1371/journal.pone.0044789

Jain, S., Chakraborty, G., Raja, R., Kale, S., and Kundu, G. C. (2008). Prostaglandin E2 regulates tumor angiogenesis in prostate cancer. Cancer Res. 68, 7750-7759. doi: 10.1158/0008-5472.CAN-07-6689

Jakobsson, P. J., Thoren, S., Morgenstern, R., and Samuelsson, B. (1999). Identification of human prostaglandin E synthase: a microsomal, glutathionedependent, inducible enzyme, constituting a potential novel drug target. Proc. Natl. Acad. Sci. U. S. A. 96, 7220-7225. doi: 10.1073/pnas.96.13.7220

Ji, Y., He, Y., Liu, L., and Zhong, X. (2010). MiRNA-26b regulates the expression of cyclooxygenase-2 in desferrioxamine-treated CNE cells. FEBS Lett. 584, 961-967. doi: 10.1016/j.febslet.2010.01.036

Jing, Q., Huang, S., Guth, S., Zarubin, T., Motoyama, A., Chen, J., et al. (2005). Involvement of microRNA in AU-rich element-mediated mRNA instability Cell 120, 623-634. doi: 10.1016/j.cell.2004.12.038

Johnstone, R. M., Mathew, A., Mason, A. B., and Teng, K. (1991). Exosome formation during maturation of mammalian and avian reticulocytes: evidence that exosome release is a major route for externalization of obsolete membrane proteins. J. Cell. Physiol. 147, 27-36. doi: 10.1002/jcp.1041470105

Kabir, T. D., Leigh, R. J., Tasena, H., Mellone, M., Coletta, R. D., Parkinson, E. K., et al. (2016). A miR-335/COX-2/PTEN axis regulates the secretory phenotype of senescent cancer-associated fibroblasts. Aging (Albany NY) 8, 1608-1635. doi: 10.18632/aging.100987

Kang, Y. J., Mbonye, U. R., Delong, C. J., Wada, M., and Smith, W. L. (2007). Regulation of intracellular cyclooxygenase levels by gene transcription and protein degradation. Prog. Lipid Res. 46, 108-125. doi: 10.1016/j.plipres. 2007.01.001

Kim, Y. K., and Kim, V. N. (2007). Processing of intronic microRNAs. Embo J. 26, 775-783. doi: 10.1038/sj.emboj.7601512

Kim, S. Y., Romero, R., Tarca, A. L., Bhatti, G., Lee, J., Chaiworapongsa, T., et al. (2011). miR-143 regulation of prostaglandin-endoperoxidase synthase 2 in the amnion: implications for human parturition at term. PLoS One 6, e24131. doi: 10.1371/journal.pone.0024131

Lagos-Quintana, M., Rauhut, R., Lendeckel, W., and Tuschl, T. (2001). Identification of novel genes coding for small expressed RNAs. Science 294, 853-858. doi: 10.1126/science.1064921

Larsson, K., and Jakobsson, P. J. (2015). Inhibition of microsomal prostaglandin E synthase- 1 as targeted therapy in cancer treatment. Prostaglandins Other Lipid Mediat. 120, 161-165. doi: 10.1016/j.prostaglandins.2015.06.002 
Lau, N. C., Lim, L. P., Weinstein, E. G., and Bartel, D. P. (2001). An abundant class of tiny RNAs with probable regulatory roles in Caenorhabditis elegans. Science 294, 858-862. doi: 10.1126/science.1065062

Leclerc, P., Idborg, H., Spahiu, L., Larsson, C., Nekhotiaeva, N., Wannberg, J., et al. (2013). Characterization of a human and murine mPGES-1 inhibitor and comparison to mPGES-1 genetic deletion in mouse models of inflammation. Prostaglandins Other Lipid Mediat. 107, 26-34. doi: 10.1016/j.prostaglandins. 2013.09.001

Lee, R. C., and Ambros, V. (2001). An extensive class of small RNAs in Caenorhabditis elegans. Science 294, 862-864. doi: 10.1126/science.1065329

Lee, S. J., Seo, K. W., and Kim, C. D. (2015). LPS Increases 5-LO Expression on monocytes via an activation of Akt-Spl/NF-kappaB pathways. Korean J. Physiol. Pharmacol. 19, 263-268. doi: 10.4196/kjpp.2015.19.3.263

Lehmann, S. M., Kruger, C., Park, B., Derkow, K., Rosenberger, K., Baumgart, J., et al. (2012). An unconventional role for miRNA: let-7 activates toll-like receptor 7 and causes neurodegeneration. Nat Neurosci. 15, 827-835. doi: 10.1038/nn.3113

Lewis, B. P., Shih, I. H., Jones-Rhoades, M. W., Bartel, D. P., and Burge, C. B. (2003). Prediction of mammalian microRNA targets. Cell 115, 787-798. doi: 10.1016/S0092-8674(03)01018-3

Li, H., Zhou, J., Wei, X., Chen, R., Geng, J., Zheng, R., et al. (2016). miR-144 and targets, c-fos and cyclooxygenase-2 (COX2), modulate synthesis of PGE2 in the amnion during pregnancy and labor. Sci. Rep. 6, 27914. doi: 10.1038/srep27914

Li, J., Kong, X., Zhang, J., Luo, Q., Li, X., and Fang, L. (2013). MiRNA-26b inhibits proliferation by targeting PTGS2 in breast cancer. Cancer Cell. Int. 13, 7. doi: 10.1186/1475-2867-13-7

Li, J., Wang, R., Ge, Y., Chen, D., Wu, B., and Fang, F. (2019). Assessment of microRNA-144-5 $\mathrm{p}$ and its putative targets in inflamed gingiva from chronic periodontitis patients. J. Periodontal Res. 54 (3), 266-277. doi: 10.1111/ jre.12627

Liu, X., Ji, Q., Zhang, C., Liu, X., Liu, Y., Liu, N., et al. (2017). miR-30a acts as a tumor suppressor by double-targeting COX-2 and BCL9 in H. pylori gastric cancer models. Sci. Rep. 7, 7113. doi: 10.1038/s41598-017-07193-w

Lu, L., Byrnes, K., Han, C., Wang, Y., and Wu, T. (2014). miR-21 targets 15-PGDH and promotes cholangiocarcinoma growth. Mol. Cancer Res. 12, 890-900. doi: 10.1158/1541-7786.MCR-13-0419

Majumder, M., Dunn, L., Liu, L., Hasan, A., Vincent, K., Brackstone, M., et al. (2018). COX-2 induces oncogenic micro RNA miR655 in human breast cancer. Sci. Rep. 8, 327. doi: 10.1038/s41598-017-18612-3

Majumder, M., Landman, E., Liu, L., Hess, D., and Lala, P. K. (2015). COX-2 elevates oncogenic miR-526b in breast cancer by EP4 Activation. Mol. Cancer Res. 13, 1022-1033. doi: 10.1158/1541-7786.MCR-14-0543

Matysiak, M., Fortak-Michalska, M., Szymanska, B., Orlowski, W., Jurewicz, A., and Selmaj, K. (2013). MicroRNA-146a negatively regulates the immunoregulatory activity of bone marrow stem cells by targeting prostaglandin E2 synthase-2. J. Immunol. 190 (10), 5102-5109. doi: 10.4049/jimmunol.1202397

Monteleone, N. J., Moore, A. E., Iacona, J. R., Lutz, C. S., and Dixon, D. A. (2019). miR-21-mediated regulation of 15-hydroxyprostaglandin dehydrogenase in colon cancer. Sci. Rep. 9, 5405. doi: 10.1038/s41598-019-41862-2

Moore, A. E., Young, L. E., and Dixon, D. A. (2012). A common single-nucleotide polymorphism in cyclooxygenase-2 disrupts microRNA-mediated regulation. Oncogene 31, 1592-1598. doi: 10.1038/onc.2011.349

Mukhopadhyay, D., Houchen, C. W., Kennedy, S., Dieckgraefe, B. K., and Anant, S. (2003). Coupled mRNA stabilization and translational silencing of cyclooxygenase-2 by a novel RNA binding protein, CUGBP2. Mol. Cell 11, 113-126. doi: 10.1016/S1097-2765(03)00012-1

Nakanishi, M., and Rosenberg, D. W. (2013). Multifaceted roles of PGE2 in inflammation and cancer. Semin. Immunopathol. 35, 123-137. doi: 10.1007/ s00281-012-0342-8

Ochs, M. J., Sorg, B. L., Pufahl, L., Grez, M., Suess, B., and Steinhilber, D. (2012). Post-transcriptional regulation of 5-Lipoxygenase mRNA expression via alternative splicing and nonsense-mediated mRNA decay. PLoS One 7, e31363. doi: 10.1371/journal.pone.0031363

Ochs, M. J., Steinhilber, D., and Suess, B. (2011). MicroRNA involved in inflammation: control of eicosanoid pathway. Front. Pharmacol. 2, 39. doi: 10.3389/fphar.2011.00039

Ochs, M. J., Steinhilber, D., and Suess, B. (2014). MicroRNAs-novel therapeutic targets of eicosanoid signalling. Basic Clin. Pharmacol. Toxicol. 114, 92-96. doi: $10.1111 /$ bcpt. 12116
Olesch, C., Sha, W., Angioni, C., Sha, L. K., Acaf, E., Patrignani, P., et al. (2015). MPGES-1-derived PGE2 suppresses CD80 expression on tumor-associated phagocytes to inhibit anti-tumor immune responses in breast cancer. Oncotarget 6, 10284-10296. doi: 10.18632/oncotarget.3581

Pettersson, P. L., Thoren, S., and Jakobsson, P. J. (2005). Human microsomal prostaglandin E synthase 1: a member of the MAPEG protein superfamily. Methods Enzymol. 401, 147-161. doi: 10.1016/S0076-6879(05)01009-8

Poligone, B., and Baldwin, A. S. (2001). Positive and negative regulation of NF-kappaB by COX-2: roles of different prostaglandins. J. Biol. Chem. 276, 38658-38664. doi: 10.1074/jbc.M106599200

Radmark, O., Werz, O., Steinhilber, D., and Samuelsson, B. (2015). 5-Lipoxygenase, a key enzyme for leukotriene biosynthesis in health and disease. Biochim. Biophys. Acta 1851, 331-339. doi: 10.1016/j.bbalip.2014.08.012

Reinhart, B. J., Slack, F. J., Basson, M., Pasquinelli, A. E., Bettinger, J. C., Rougvie, A. E., et al. (2000). The 21-nucleotide let-7 RNA regulates developmental timing in Caenorhabditis elegans. Nature 403, 901-906. doi: 10.1038/35002607

Samuelsson, B., Morgenstern, R., and Jakobsson, P. J. (2007). Membrane prostaglandin E synthase-1: a novel therapeutic target. Pharmacol. Rev. 59, 207-224. doi: 10.1124/ pr.59.3.1

Sato, T., Liu, X., Nelson, A., Nakanishi, M., Kanaji, N., Wang, X., et al. (2010). Reduced miR-146a increases prostaglandin E(2)in chronic obstructive pulmonary disease fibroblasts. Am. J. Respir. Crit. Care Med. 182, 1020-1029. doi: 10.1164/rccm.201001-0055OC

Saul, M. J., Baumann, I., Bruno, A., Emmerich, A. C., Wellstein, J., Ottinger, S. M., et al. (2019). miR-574-5p as RNA decoy for CUGBP1 stimulates human lung tumor growth by mPGES-1 induction. Faseb J. 33 (6), 6933-6947. doi: 10.1096/ f. $201802547 \mathrm{R}$

Saul, M. J., Stein, S., Grez, M., Jakobsson, P. J., Steinhilber, D., and Suess, B. (2016). UPF1 regulates myeloid cell functions and S100A9 expression by the hnRNP E2/miRNA-328 balance. Sci. Rep. 6, 31995. doi: 10.1038/srep31995

Sawaoka, H., Dixon, D. A., Oates, J. A., and Boutaud, O. (2003). Tristetraprolin binds to the 3'-untranslated region of cyclooxygenase-2 mRNA. A polyadenylation variant in a cancer cell line lacks the binding site. J. Biol. Chem. 278, 13928-13935. doi: 10.1074/jbc.M300016200

Shanmugam, N., Reddy, M. A., and Natarajan, R. (2008). Distinct roles of heterogeneous nuclear ribonuclear protein $\mathrm{K}$ and microRNA-16 in cyclooxygenase-2 RNA stability induced by S100b, a ligand of the receptor for advanced glycation end products. J. Biol. Chem. 283, 36221-36233. doi: 10.1074/jbc.M806322200

Shao, Y., Li, P., Zhu, S. T., Yue, J. P., Ji, X. J., Ma, D., et al. (2016). MiR-26a and miR144 inhibit proliferation and metastasis of esophageal squamous cell cancer by inhibiting cyclooxygenase-2. Oncotarget 7, 15173-15186. doi: 10.18632/ oncotarget.7908

Shurtleff, M. J., Temoche-Diaz, M. M., Karfilis, K. V., Ri, S., and Schekman, R. (2016). Y-box protein 1 is required to sort microRNAs into exosomes in cells and in a cell-free reaction. eLife 5, e19276. doi: 10.7554/eLife.19276

Steinhilber, D., and Hofmann, B. (2014). Recent advances in the search for novel 5-lipoxygenase inhibitors. Basic Clin. Pharmacol. Toxicol. 114, 70-77. doi: 10. $1111 /$ bcpt. 12114

Steinhilber, D., Radmark, O., and Samuelsson, B. (1993). Transforming growth factor beta upregulates 5-lipoxygenase activity during myeloid cell maturation. Proc. Natl. Acad. Sci. U. S. A. 90, 5984-5988. doi: 10.1073/pnas.90.13.5984

Strillacci, A., Griffoni, C., Sansone, P., Paterini, P., Piazzi, G., Lazzarini, G., et al. (2009). MiR-101 downregulation is involved in cyclooxygenase-2 overexpression in human colon cancer cells. Exp. Cell. Res. 315, 1439-1447. doi: 10.1016/j.yexcr.2008.12.010

Su, K., Wang, Q., Qi, L., Hua, D., Tao, J., Mangan, C. J., et al. (2016). MicroRNA-674$5 \mathrm{p} / 5$-LO axis involved in autoimmune reaction of Concanavalin A-induced acute mouse liver injury. Toxicol. Lett. 258, 101-107. doi: 10.1016/j.toxlet.2016.06.010

Subbaramaiah, K., Marmo, T. P., Dixon, D. A., and Dannenberg, A. J. (2003). Regulation of cyclooxgenase- 2 mRNA stability by taxanes: evidence for involvement of p38, MAPKAPK-2, and HuR. J. Biol. Chem. 278, 37637-37647. doi: $10.1074 /$ jbc.M301481200

Suzuki, J., Ogawa, M., Watanabe, R., Takayama, K., Hirata, Y., Nagai, R., et al. (2011). Roles of prostaglandin E2 in cardiovascular diseases. Int. Heart J. 52, 266-269. doi: 10.1536/ihj.52.266

Taganov, K. D., Boldin, M. P., Chang, K. J., and Baltimore, D. (2006). NF-kappaBdependent induction of microRNA miR-146, an inhibitor targeted to signaling 
proteins of innate immune responses. Proc. Natl. Acad. Sci. U. S. A. 103, 1248112486. doi: $10.1073 /$ pnas. 0605298103

Tanaka, T., Haneda, S., Imakawa, K., Sakai, S., and Nagaoka, K. (2009). A microRNA, miR-101a, controls mammary gland development by regulating cyclooxygenase-2 expression. Differentiation 77, 181-187. doi: 10.1016/j.diff.2008.10.001

Terzuoli, E., Donnini, S., Finetti, F., Nesi, G., Villari, D., Hanaka, H., et al. (2016). Linking microsomal prostaglandin E Synthase-1/PGE-2 pathway with miR$15 \mathrm{a}$ and -186 expression: novel mechanism of VEGF modulation in prostate cancer. Oncotarget 7, 44350-44364. doi: 10.18632/oncotarget.10051

Thery, C., Witwer, K. W., Aikawa, E., Alcaraz, M. J., Anderson, J. D., Andriantsitohaina, R., et al. (2018). Minimal information for studies of extracellular vesicles 2018 (MISEV2018): a position statement of the International Society for Extracellular Vesicles and update of the MISEV2014 guidelines. J. Extracell. Vesicles 7, 1535750. doi: 10.1080/20013078.2018.1535750

Villarroya-Beltri, C., Gutierrez-Vazquez, C., Sanchez-Cabo, F., Perez-Hernandez, D., Vazquez, J., Martin-Cofreces, N., et al. (2013). Sumoylated hnRNPA2B1 controls the sorting of miRNAs into exosomes through binding to specific motifs. Nat. Commun. 4, 2980. doi: 10.1038/ncomms3980

Wang, D., and Dubois, R. N. (2006). Prostaglandins and cancer. Gut 55, 115-122. doi: 10.1136/gut.2004.047100

Wang, D., and Dubois, R. N. (2010). Eicosanoids and cancer. Nat. Rev. Cancer 10, 181-193. doi: $10.1038 / \mathrm{nrc} 2809$

Wang, D., Li, Y., Zhang, C., Li, X., and Yu, J. (2018). MiR-216a-3p inhibits colorectal cancer cell proliferation through direct targeting COX-2 and ALOX5. J. Cell. Biochem. 119, 1755-1766. doi: 10.1002/jcb.26336

Wang, H. W., Hsueh, C. T., Lin, C. F., Chou, T. Y., Hsu, W. H., Wang, L. S., et al. (2006). Clinical implications of microsomal prostaglandin e synthase-1 overexpression in human non-small-cell lung cancer. Ann. Surg. Oncol. 13, 1224-1234. doi: 10.1245/ s10434-006-9001-4

Wang, R., Li, M., Zhou, S., Zeng, D., Xu, X., Xu, R., et al. (2015). Effect of a single nucleotide polymorphism in miR-146a on COX-2 protein expression and lung function in smokers with chronic obstructive pulmonary disease. Int J. Chron. Obstruct. Pulmon. Dis. 10, 463-473. doi: 10.2147/COPD.S74345

Wang, Z., Filgueiras, L. R., Wang, S., Serezani, A. P., Peters-Golden, M., Jancar, S., et al. (2014). Leukotriene B4 enhances the generation of proinflammatory microRNAs to promote MyD88-dependent macrophage activation. J. Immunol. 192, 2349-2356. doi: 10.4049/jimmunol.1302982

Wen, C., Seeger, R. C., Fabbri, M., Wang, L., Wayne, A. S., and Jong, A. Y. (2017). Biological roles and potential applications of immune cell-derived extracellular vesicles. J. Extracell. Vesicles 6, 1400370. doi: 10.1080/20013078.2017.1400370

Wightman, B., Ha, I., and Ruvkun, G. (1993). Posttranscriptional regulation of the heterochronic gene lin-14 by lin-4 mediates temporal pattern formation in C. elegans. Cell 75, 855-862. doi: 10.1016/0092-8674(93)90530-4

Wu, Y. C., Su, L. J., Wang, H. W., Jeff Lin, C. F., Hsu, W. H., Chou, T. Y., et al. (2010). Co-overexpression of cyclooxygenase- 2 and microsomal prostaglandin
E synthase-1 adversely affects the postoperative survival in non-small cell lung cancer. J. Thorac Oncol. 5, 1167-1174. doi: 10.1097/JTO.0b013e3181e2f4f5

Yamamoto, K., Arakawa, T., Ueda, N., and Yamamoto, S. (1995). Transcriptional roles of nuclear factor kappa B and nuclear factor-interleukin-6 in the tumor necrosis factor alpha-dependent induction of cyclooxygenase- 2 in MC3T3-E1 cells. J. Biol. Chem. 270, 31315-31320. doi: 10.1074/jbc.270.52. 31315

Yao, L., Han, C., Song, K., Zhang, J.,Lim, K., and Wu, T. (2015). Omega-3 polyunsaturated fatty acids upregulate 15-PGDH expression in cholangiocarcinoma cells by inhibiting miR-26a/b expression. Cancer Res. 75, 1388-1398. doi: 10.1158/00085472.CAN-14-2561

Yao, S., Xu, J., Zhao, K., Song, P., Yan, Q., Fan, W., et al. (2018). Down-regulation of HPGD by miR-146b-3p promotes cervical cancer cell proliferation, migration and anchorage-independent growth through activation of STAT3 and AKT pathways. Cell. Death Dis. 9, 1055. doi: 10.1038/s41419-018-1059-y

Yoshimatsu, K., Altorki, N. K., Golijanin, D., Zhang, F., Jakobsson, P. J., Dannenberg, A. J., et al. (2001a). Inducible prostaglandin E synthase is overexpressed in non-small cell lung cancer. Clin. Cancer Res. 7, 2669-2674.

Yoshimatsu, K., Golijanin, D., Paty, P. B., Soslow, R. A., Jakobsson, P. J., Delellis, R. A., et al. (2001b). Inducible microsomal prostaglandin E synthase is overexpressed in colorectal adenomas and cancer. Clin. Cancer Res. 7, 3971-3976.

Young, L. E., and Dixon, D. A. (2010). Posttranscriptional regulation of cyclooxygenase 2 expression in colorectal cancer. Curr. Colorectal Cancer Rep. 6, 60-67. doi: 10.1007/s11888-010-0044-3

Zeldin, D. C. (2001). Epoxygenase pathways of arachidonic acid metabolism. J. Biol. Chem. 276, 36059-36062. doi: 10.1074/jbc.R100030200

Zhang, J., Li, S., Li, L., Li, M., Guo, C., Yao, J., et al. (2015). Exosome and exosomal microRNA: trafficking, sorting, and function. Genomics Proteomics Bioinf. 13, 17-24. doi: 10.1016/j.gpb.2015.02.001

Zhang, W., Xiao, J., Lu, X., Liu, T., Jin, X., Xiao, Y., et al. (2019). PVT1 (rs13281615) and miR-146a (rs2910164) polymorphisms affect the prognosis of colon cancer by regulating COX2 expression and cell apoptosis. J. Cell. Physiol. 234 (10), 17538-17548. doi: 10.1002/jcp.28377

Conflict of Interest Statement: The authors declare that the research was conducted in the absence of any commercial or financial relationships that could be construed as a potential conflict of interest.

Copyright $\odot 2019$ Saul, Emmerich, Steinhilber and Suess. This is an open-access article distributed under the terms of the Creative Commons Attribution License (CC BY). The use, distribution or reproduction in other forums is permitted, provided the original author $(s)$ and the copyright owner(s) are credited and that the original publication in this journal is cited, in accordance with accepted academic practice. No use, distribution or reproduction is permitted which does not comply with these terms. 